\title{
The keys to the kingdom. \\ Overcoming GDPR-concerns to unlock access to platform data for independent researchers ${ }^{1}$
}

\author{
Dr. Mathias Vermeulen²
}

\begin{abstract}
Independent researchers have requested access to a wide variety of platform data in order to scrutinize the actors and methods responsible for the spreading of disinformation, as well as to assess the effectiveness and impact of the self-regulatory measures platforms have taken to counter disinformation. Over the past two years the European Union has increasingly supported these requests, including by facilitating the adoption of the EU Code of Practice on Disinformation, in which platforms committed themselves to provide such access through a variety of mechanisms. However, both European decision makers and researchers have consistently criticized the insufficiency of these mechanisms. On a number of occasions platforms have invoked their obligations under the EU's General Data Protection Regulation (GDPR) as rationale for failing to make certain data sets available. This paper aims to assess those claims in order to clarify to which extent, if any, GDPR concerns prevent the disclosure of (sensitive) personal data by platforms to independent researchers. The paper will argue that the GDPR currently allows the sharing of personal data for such purposes in a number of ways, but recommends the adoption of a binding legal obligation for platforms to hand over data and a Code of Conduct on Access To Platform Data under Article 40 of the GDPR as necessary measures to provide more legal certainty about the specific roles and responsibilities of both platforms and independent researchers.
\end{abstract}

\footnotetext{
${ }^{1}$ Draft submitted to the Knight First Amendment Institute at Columbia University, Data And Democracy Symposium, 15-16 October 2020. For more info see https://knightcolumbia.org/events/data-and-democracy.

2 Public Policy Director, AWO, and Associate Fellow at the Centre for Law, Science and Technology Studies at the Vrije Universiteit Brussel. The author is grateful to Alex Abdo, Jef Ausloos, Cristina Blasi Casagran, Jameel Jaffer, Julian Jaursch, Amy Kapczynski, Paddy Leerssen, Claudia Prettner and Rebekah Tromble for helpful guidance, feedback, and conversations on this topic and early drafts. Special thanks to Ravi Naik and Daphne Keller for providing detailed comments on the GDPR-related analysis. All errors remain my own. This research was financially supported by the Mozilla Foundation and Reset.
} 
"Although we have more data than ever before, a smaller percentage of that data is available to researchers than ever before". ${ }^{3}$

Over the last two years a number of large platforms have made independent research more difficult by restricting scholars' access to their application programming interfaces. Equally, initiatives that were specifically designed to provide scholars with access to personal data have fallen far short of expectations. Third parties are dependent on metrics determined and voluntarily released by the platforms themselves, with few ways to verify them ${ }^{4}$. This article argues that there is a pressing societal need for a legally binding mechanism that provides independent researchers with access to a range of different types of platform data. In general, this mechanism would allow for the identification and understanding of the profound impacts, both positive and negative, that digital platforms have on societies. This is needed to overcome an enormous information asymmetry between platforms and third parties, in particular independent researchers.

The need for greater access to data is illustrated in this article by focussing on one specific key policy discussion: the role of social media platforms in enabling, facilitating and amplifying disinformation. Access to platform data in this context would have at least three key benefits. It would allow for more scrutiny into the influence of platforms' core infrastructure - such as ad targeting mechanisms or content recommendation algorithms - on the dissemination of disinformation. It would facilitate the detection of organized disinformation campaigns by state actors that try to manipulate elections. And it would enable closer scrutiny of the effectiveness and proportionality of specific, voluntary, interventions by the platforms to counter disinformation. This increased transparency could in turn enable regulators to create evidencebased policies to hold platforms to account if and when they are responsible for facilitating or exacerbating harms caused by disinformation.

Contrary to the situation in the United States, there is a window of opportunity in the European Union to establish such a mechanism. The Vice-President of the European Commission has stated that the Commission would need to "address issues such as access and use of data" in order to "build the resilience of our democracies" against the threats of disinformation ${ }^{5}$. Another Vice-President of the European Commission has stated that "countering disinformation and making our societies more resilient to manipulation is a common priority for EU institutions and Member States, singling out the need for "better transparency rules and better cooperation when it comes to access to data and the use of algorithms". ${ }^{6}$

Platforms have often invoked Europe's General Data Protection Regulation (GDPR) as a key obstacle that prevents them from sharing platform data, including personal data with independent researchers. In general, their argument rests on the assumption that the GDPR lacks clarity regarding whether and how companies might share data with independent researchers, which results in a conservative attitude to make such data available given the fines that can be incurred for violating the GDPR. Additionally, the

\footnotetext{
${ }^{3}$ Social Science One, Building Infrastructure for Studying Social Media's Role in Elections and Democracy, 27 August 2019 available at https://socialscience.one/blog/building-infrastructure-studying-social-media's-role-electionsand-democracy $\% \mathrm{C} 2 \% \mathrm{~A} 0$

${ }^{4}$ Alexandre Alaphilippe, Adding a 'D' to the ABC disinformation framework. Brookings, 27 April 2020, available at https://www.brookings.edu/techstream/adding-a-d-to-the-abc-disinformation-framework/

${ }^{5}$ Vera Jourova, Answers to the European Parliament - Questionnaire to the Commissioner-Designate, 29 September 2019 available at https://ec.europa.eu/commission/commissioners/sites/commcwt2019/files/commissioner ep hearings/answers-ep-questionnaire-jourova.pdf

${ }^{6}$ Josep Borrell, Answers to the European Parliament - Questionnaire to the Commissioner-Designate, available at https://www.europarl.europa.eu/resources/library/media/20190927RES62426/20190927RES62426.pdf
} 
release of such data could result in evidence-based criticism, public outcry and regulatory action, which means there is currently little to no incentive for platforms to hand over such data.

After analysing the societal benefits for providing researchers with access to platform data (section 1), and describing the increasing regulatory appetite in the European Union to create a mandatory legal access regime for platform data (section 2), this article will assess the effectiveness of those voluntary mechanisms that platforms have provided to date that allow researchers access to their data (sections 3 and 4). One potential infrastructural solution is explored in section 5 , which could address some of the deficiencies in those voluntary mechanisms.

While this article focuses on independent researchers as one specific category of beneficiaries who require access to data to pursue scientific research, researchers could also get access to data on behalf of a regulator for the purposes of monitoring and assessing the compliance of platforms with new obligations that the EU could impose on platforms. These obligations could include, for example, measures that would protect the general public from health misinformation or election manipulation. In that specific context, this article argues that a new legal obligation should be imposed on platforms to hand over all relevant data to pre-vetted researchers that act on its behalf. Section 6 , and in particular section 6.4 explores this scenario more in depth. Section 7 of this paper then provides an initial assessment of some of the more detailed questions that arise in relation to the GDPR's research exemption in article 89, which are relevant to consider independent from the legal basis of the data processing.

This article finally argues that an effective data disclosure framework in the form of a Code of Conduct to Access to Platform Data under Article 40 of the GDPR could provide more legal certainty about the proper application of the GDPR in this context. Section 8 of this paper describes ultimately how such a Code could specify the modalities and safeguards for researchers' data access, and provide platforms with more legal certainty while ensuring the independence of the research.

\section{Researchers' requests for access to data as a crucial tool to analyze and mitigate the harms resulting from disinformation}

Over the past couple of years independent researchers whose work aims to analyze, detect, expose or prevent the creation, facilitation, dissemination and impact of disinformation online have systematically requested access to a wide variety of platform data. This article will focus specifically on scientific researchers, as article 89 GDPR and recital 159 list specific rules for the processing of personal data for scientific purposes. However, as Leerssen rightly points out, limiting access to academic researchers "cannot make up for the full breadth of civil society watchdog functions in media governance, which have also been performed by journalists, activists, NGOs and political campaigners".

Platform data - or just 'data' - is often used as an amorphous all-encompassing term that hides at least three different categories of data, which in the European Union would be afforded different levels of legal protection under the General Data Protection Regulation (GDPR). ${ }^{7}$

The first category consists of predominantly non-personal data which is often proprietary; this can consist of numerical data, metrics, classifiers or other types of data that relate to the technical functionalities,

\footnotetext{
${ }^{7}$ Determining who qualifies as a 'researcher' for the purposes of providing them with access to data is one of the questions that a Code of Conduct could work out (see sections 7 and 8 of this paper).
} 
design choices or policy decisions of a particular platform. These can include, for instance, statistics about $\mathrm{a} / \mathrm{b}$ testing ${ }^{8}$, information about microtargeting options used by advertisers ${ }^{9}$; engagement and impression data of watched videos; data that enables network analysis of a video recommendation system $^{10}$; or internal categorizations of specific pieces of content or metrics regarding the enforcement of specific Terms-of-Services violations. This category also includes data about the parameters that determine the ranking, sequencing, rating or review mechanisms of content, visual highlights, or other saliency tools. ${ }^{11}$ In the European Union, platforms are already required to outline these parameters "in order to improve predictability" for business users (such as restaurants, travel agents or shops) to allow them to "better understand the functioning of the ranking mechanism and to enable them to compare the ranking practices of various providers". ${ }^{12}$ The GDPR does not apply to this data insofar as it is not "personal"13 data.

A second category of data consists of personal data, which according to the GDPR refers to any information relating to an identified or identifiable natural person ('data subject'). Essentially, personal data is any type of data that relates to a natural person or can reveal the identity of a user of a specific platform, for example, the account information or IP-addresses of individual users. The sharing of such data is subject to a number of rules and safeguards.

A third category of data consists of "sensitive" or "special category" personal data, which according to the GDPR refers to data that can reveal someone's "racial or ethnic origin, political opinions, religious or philosophical beliefs, or trade union membership". ${ }^{14}$ It also includes health data or data "concerning a natural person's sex life or sexual orientation"15. The processing or sharing of such special category data is in principle prohibited, unless an exception to this general principle applies.

Researchers need access to these different categories of data for a wide variety of investigations relating to public discourse, including investigations that study (i) organized disinformation campaigns by state actors; (ii) other pathologies (e.g. misinformation, discrimination, harassment) that stem from the actions of platforms' users; (ii) the influence on public discourse of the platforms' own policies and decisions.

One very precise purpose for which access to data is needed is to attribute organized disinformation campaigns to specific, well-funded, state or non-state actors. The detection of manipulative actors who engage knowingly and covertly in what Camille Francois dubbed "viral deception campaigns" relies on a "cat-and-mouse game of a) identifying threat actors willing and able to covertly manipulate public discourse and b) keeping those actors from leveraging social media to do so, as they refine their

\footnotetext{
${ }^{8} \mathrm{~A} / \mathrm{b}$-testing consists of a randomized experiment with two variants, $A$ and $B$, in which two versions of a single variable are tested, typically by testing a subject's response to variant $A$ against variant $B$, and determining which of the two variants is more effective.

${ }^{9}$ See for instance Mozilla, Facebook and Google: This is What an Effective Ad Archive API Looks Like https://blog.mozilla.org/blog/2019/03/27/facebook-and-google-this-is-what-an-effective-ad-archive-api-looks-like/

${ }^{10}$ See for instance Brandi Geurkink, Our recommendation to YouTube, 14 October 2019 https://foundation.mozilla.org/en/blog/our-recommendation-youtube/

${ }^{11}$ EU Regulation (EU) 2019/1150 of the European Parliament and of the Council of 20 June 2019 on promoting fairness and transparency for business users of online intermediation services §24: "The notion of main parameter should be understood to refer to any general criteria, processes, specific signals incorporated into algorithms or other adjustment or demotion mechanisms used in connection with the ranking".

12 Idem.

13 GDPR Article 4.1

14 GDPR Article 9.1

15 Idem.
} 
strategies to evade detection ${ }^{16}$. Francois highlighted the "dramatic asymmetry of information" between the platforms on whose infrastructure these influence operations play out, and the rest of the world, in her briefing for the United States House of Representatives Committee on Science, Space and Technology. There she lambasted that some platforms' community standards or terms of service either 'indirectly prevent the type of external research that may lead to detecting and exposing distortive behaviors (e.g., when existing and important safeguards also prevent researchers from collecting the data they'd need to analyze distortive behaviors) or directly seek to prevent it (e.g., with rules explicitly preventing the use of data in order to perform detection of deceptive behavior)". ${ }^{17}$

Francois received access to non-public platform data on behalf of the US Senate Intelligence Committee to scrutinize the Russian campaign targeting the American public around the 2016 presidential election. Her conclusion, even with that unprecedented access, after seven months of intense research was that "[t]here remain critical data blind spots (...) which undermine our preparation for the threats ahead"18. Research that focuses on attribution is essentially an extended field of research for cybersecurityscholars and -practitioners, which have been very critical about the lack of data from platforms. ${ }^{19}$ Pamment points out that the security teams at the major platforms already have an "open, trusted channel for sharing intelligence on disinformation leads and threat actor tactics, techniques, and procedures" - in contrast to other business areas, which indicates in his view at least the "feasibility of collaborating on a shared repository of analytics and campaign-wide data for (...) the research community". 20

Access to this data would also be very helpful for international law scholars. Article 25 of the International Covenant on Civil and Political Rights (ICCPR) provides the right to vote and participate in public affairs. According to the UN Human Rights Committee, which interprets the ICCPR, this requires voters to be able to "form opinions independently" without any "manipulative interference of any kind". ${ }^{21}$ Currently there is little guidance about what this standard would mean in an era of information operations: when do such operations reach the level of 'manipulative interference'?

Platforms have prohibited these practices in their Terms of Services, which prohibit coordinated efforts to manipulate public debate for a strategic goal. ${ }^{22}$ However, uncovering malicious behavior and inaccurate messages from state actors - or other 'bad' actors - is only one goal of a subset of disinformation researchers. Another crucial reason why disinformation scholars want to have access to data is to assess the effectiveness and proportionality of specific, voluntary interventions by the platforms to counter

\footnotetext{
${ }^{16}$ Camille Francois, Actors, Behavior, Content: A disinformation ABC. Transatlantic High Level Working Group on Content Moderation Online and Freedom of Expression, p.xx https://science.house.gov/imo/media/doc/Francois \%20Addendum $\% 20$ to\%20Testimony $\% 20$ \%20ABC Framework 2019 Sept 2019.pdf

17 Idem.

${ }^{18}$ Graphika, Briefing for the United States House of Representatives Committee on Science, Space, and Technology, 26 September 2019, available at https://science.house.gov/imo/media/doc/Francois\%20Testimony.pdf , p.4

${ }^{19}$ See also Thomas Ridt, Disinformation: a primer in Russian active measures and influence campaigns. Hearing before the US Senate Select Committee on Intelligence, 30 March 2017,p. 5-6 available at https://www.intelligence.senate.gov/sites/default/files/documents/os-trid-033017.pdf

20 James Pamment, EU Code of Practice on Disinformation: Briefing Note for the New European Commission available at https://carnegieendowment.org/2020/03/03/eu-code-of-practice-on-disinformation-briefing-note-for-neweuropean-commission-pub-81187

${ }^{21}$ U.N. Human Rights Committee., General Comment No. 25 (57), U.N. Doc. CCPR/C/2/Rev.1/Add.7 (Aug 27, 1996) at para.8

22 See for instance Facebook's Community standards

https://www.facebook.com/communitystandards/inauthentic behavior or Twitter's policy on platform manipulation https://help.twitter.com/en/rules-and-policies/platform-manipulation
} 
disinformation. A recent report by the Institute for Strategic Dialogue on the activities of social media platforms to counter COVID-19-related misinformation illustrates how platforms have responded quickly to the challenges posed by bad actors, including by setting up information hubs that share verified updates from trusted sources such as the World Health Organisation; labelling, downranking and/or removing content flagged as false or misleading by experts; and prohibiting ads that aim to profiteer off the pandemic. Unfortunately, there is no way to independently assess the effectiveness of these interventions. Statistics that are given need to be accepted at face-value, claimed successes cannot be independently verified. As the ISD notes:

Without better access to data and insight on companies' decision-making systems, both humanand machine-led, we cannot determine with certainty why some areas of policy appear more effective or better enforced than others. (...) Without such data any conclusions drawn about the response of these platforms must rely on some element of extrapolation and inference ${ }^{23}$.

Platforms have taken a number of measures in the past five years to counter various symptoms of the disinformation problem, including by updating their Terms of Services to outline which specific activities are prohibited on their platforms. However, most of these interventions focus on the behavior of 'bad' external - actors; they rarely address the core enabling infrastructure of the platforms in facilitating the spreading and amplification of disinformation. This core architecture consists of a series of in-built optimisation rules, engagement algorithms and incentives structures that are intended features of platforms like Facebook, YouTube and Twitter. Active design choices are made about this coreinfrastructure with the primary goal of harvesting our attention to enable targeted, mostly automated, advertising at a very large scale. ${ }^{24}$ These features determine access to information, its amplification and ultimately the reach of specific pieces of content. These are the same features that are used - and gamed - by every influencer or online marketer that wants to push a specific message. 'Bad actors' in that sense are using often the same tools that legitimate business users have at their disposal. ${ }^{25}$

This is illustrated by the fact that despite all the voluntary actions to counter COVID-19-related misinformation by the platforms, that information is still rampant - assumingly because content promotion and amplification systems are largely left untouched by these actions ${ }^{26}$. According to a recent study published in BMJ Global Health, over $25 \%$ of the most viewed YouTube videos about coronavirus contain false or misleading information, which has led to suggestions that COVID-19 related misinformation is being pushed more frequently than verified health content. Another recent investigation by ISD and the $\mathrm{BBC}$ found that websites known to host disinformation about COVID-19 had received over 80 million

${ }^{23}$ Chloe Colliver, Jennie King, The First 100 Days: Coronavirus and crisis management on social media platforms. ISD, 2020 available at https://www.isdglobal.org/wp-content/uploads/2020/06/20200515-ISDG-100-days-BriefingV5.pdf at p.5. On this point see also Ranking Digital Rights, Getting to the Source of Infodemics: It's the Business Model (May 2020), pp 8-9 available at https://www.newamerica.org/oti/reports/getting-to-the-source-of-infodemics-itsthe-business-model/

${ }^{24}$ Zeynep Tufekci, It's the (Democracy-Poisoning) Golden Age of Free Speech. Wired, 16 January 2018 available at https://www.wired.com/story/free-speech-issue-tech-turmoil-new-censorship/ See also Facebook co-founder Chris Hughes' statement: "'Facebook's business model is built on capturing as much of our attention as possible to encourage people to create and share more information about who they are and who they want to be." https://www.nytimes.com/2019/05/09/opinion/sunday/chris-hughes-facebook-zuckerberg.html

${ }_{25}$ Park Advisors, Weapons of Mass Distraction: Foreign State-Sponsored Disinformation in the Digital Age https://www.state.gov/wp-content/uploads/2019/05/Weapons-of-Mass-Distraction-Foreign-State-SponsoredDisinformation-in-the-Digital-Age.pdf at p.36. The EU High Level Expert Group on Fake News and Disinformation stated that it "is clear that many of the tools integral to the contemporary digital ecosystem that are used for legitimate purposes- e.g. behavioural data collection, analytics, advertising exchanges, tools for cluster detection and tracking social media sentiment, and various forms of Al/machine learning-have also been harnessed by some purveyors of disinformation". https://ec.europa.eu/digital-single-market/en/news/final-report-high-level-expert-group-fake-newsand-online-disinformation, p.12.

${ }^{26}$ Chloe Colliver, Jennie King, The First 100 Days: Coronavirus and crisis management on social media platforms. 
interactions on public Facebook pages since the start of the year. As a benchmark, in the same period, links to the CDC and WHO websites gathered around 12 million interactions combined. ${ }^{27}$ In another area, the New York Times suggested that Facebook's recommendations systems, designed to prioritize the growth of closed groups, "most likely supercharged the QAnon community - exposing scores of people to the conspiracy theory". ${ }^{28}$

When evidence emerges about the enabling role of this core infrastructure in facilitating the amplification and dissemination of disinformation, no action ensues - unless undeniable evidence is made public. When an internal report at Facebook, obtained by the Wall Street Journal, found that 64 percent of people who joined an extremist group on Facebook only did so because the company's algorithm recommended it to them - no follow up action ensued. ${ }^{29}$ But when The Markup published a story about how Facebook allowed advertisers to target people who were interested in 'pseudoscience', the company removed this targeting option. ${ }^{30}$ Hence researchers want access to any relevant source data, which mainly includes proprietary data but also personal and sensitive data, in order to properly scrutinize the role of this core architecture in amplifying and dissemination disinformation.

Similarly, more granular data access is needed to scrutinize the rare interventions by companies in their core infrastructure. For instance, YouTube claimed in December 2019 that US users spent on average 70 percent less time watching videos that it deems "borderline" content, such as flat-earth conspiracy myths, after tweaking its recommendation algorithm. But there is absolutely no way to scrutinize that figure. YouTube didn't release any underlying figures, such as how much time viewers still spend watching the videos, which sample size it used or how many people click on the top videos under a given search or in what order. ${ }^{31}$ Yet there is currently no independent data-sharing mechanism which allows for a proper independent analysis by any independent third party - be it a regulator or an independent researcher.

Besides these concrete reasons to have access to platform data, there is a more general demand for data from a whole range of academic disciplines, from communication studies to psychology, which are keen to have access to platform data, in particular personal data, in order to improve the analysis of a broad range of socio-cultural phenomena. Researchers are keen to have access to (sensitive) personal data to learn about the behaviour of small groups or individuals, ${ }^{32}$ since the ability to study how people communicate and interact on social media is of vital importance for social science, and arguably for society as a whole. In announcing one of Facebook's latest data-sharing efforts, Nick Clegg, Vice President for Global Affairs and Communications admitted that there is a need for "more objective, dispassionate, empirically grounded research". According to Clegg, "we need to better understand whether social media makes us more polarized as a society, or if it largely reflects the divisions that

\footnotetext{
27 Idem.

${ }^{28}$ Charlie Warzel, The week QAnon went mainstream. NYTimes, 15 August 2020, available at https://www.nytimes.com/2020/08/15/opinion/qanon-marjorie-greene-congress.html

29 Jeff Horwitz, Deepa Seetharman, Facebook Executives Shut Down Efforts to Make the Site Less Divisive. Wall Street Journal, 26 May 2020, available at https://www.wsj.com/articles/facebook-knows-it-encourages-division-topexecutives-nixed-solutions-11590507499?mod=hp lead pos5

${ }_{30}$ Aaron Sankin, Want to find a misinformed public? Facebook's already done it. The Markup, 23 april 2020 https://themarkup.org/coronavirus/2020/04/23/want-to-find-a-misinformed-public-facebooks-already-done-it

${ }^{31}$ Greg Bensinger, YouTube says viewers are spending less time watching conspiracy theory videos. But many still do. Washington Post, 3 December 2019 available at https://www.washingtonpost.com/technology/2019/12/03/youtube-says-viewers-are-spending-less-time-watchingconspiracy-videos-many-still-do/

${ }_{32}$ Gary King, Nate Persily, Unprecedented Facebook URLs Dataset now Available for Academic Research through Social Science One. Social Science One, 13 February 2020, available athttps://socialscience.one/blog/unprecedented-facebook-urls-dataset-now-available-research-through-socialscience-one
} 
already exist; if it helps people to become better informed about politics, or less; or if it affects people's attitudes towards government and democracy, including whether and how they vote". ${ }^{33}$

Until very recently (see point 4 below) researchers who wanted to tap into this data creatively repurposed data APIs that were originally made for developers or used scraping methods to get access to data. Both methods have a range of flaws and difficulties, which result in partial access to data that is "biased, incomplete, and subject to a range of awkward technical and contractual restrictions that impede its usefulness for empirical research ${ }^{34}$. Puschman concludes

A host of problems including the influence of misinformation campaigns and the root causes of aggressive online behavior could be studied and possibly addressed more effectively if scholars had access to social media data in a manner that satisfies scientific standards, which the use of developer APIs and scraping both do not. ${ }^{35}$

\section{The increasing interest from the European Union in forcing platforms to make platform data available for the public interest}

The EU's interest in countering disinformation has for a long time focused almost exclusively on countering narratives and false information originating from Russia. After the annexation of Crimea by Russia and the downing of flight MH17 in 2014, the problem of Russian disinformation became even more salient. Indeed, the European Council, which consists of the heads of state or government of the EU's member states, stressed in 2015 the need to challenge Russia's ongoing disinformation campaigns with the establishment of a "communication team"36 - East Stratcom - to debunk disinformation narratives ${ }^{37}$ Similarly, in the wake of the 2016 U.S. presidential election, many European governments increased their efforts and set up their own national specialized teams to detect and counter information operations, including by enhancing their strategic communications. ${ }^{38}$ According to an investigation by Politico in November 2019, the effectiveness of these teams "has been patchy at best". Politico cited "limited access to data from social media companies - where much of this misinformation is spread" as a key reason that has hamstrung these efforts. ${ }^{39}$ That data is needed to properly attribute disinformation campaigns to foreign or hostile actors, as it can give details such as which source initially created or shared content for the first time. Data that allows for the attribution of information operations is crucial to formulate proportionate (counter) responses that might deter similar behavior from taking place in the future.

\footnotetext{
${ }^{33}$ Nick Clegg, Chay Nayak, New Facebook and Instagram Research Initiative to Look at US 2020 Presidential Election, 31 August 2020, available at https://about.fb.com/news/2020/08/research-impact-of-facebook-andinstagram-on-us-election/

${ }^{34}$ Cornelius Puschmann (2019): An end to the wild west of social media research: a response to Axel Bruns, Information, Communication \& Society, DOI: 10.1080/1369118X.2019.1646300 at 7.

35 Idem.

${ }^{36}$ European Council Conclusions, 20 March 2015, available

athttps://www.consilium.europa.eu/media/21888/european-council-conclusions-19-20-march-2015-en.pdf

37 European Commission and the EU High Representative of the Union for Foreign Affairs and Security Policy, Joint report to the European Parliament and the Council on the implementation of the Joint Framework on countering hybrid threats - a European Union response, available at ehttps://eur-lex.europa.eu/legalcontent/EN/TXT/PDF/?uri=CELEX:52017JC0030\&from=EN p.5 NATO has a strategic communications cell since 2007 https://www.europarl.europa.eu/RegData/etudes/BRIE/2016/586600/EPRS BRI\%282016\%29586600 EN.pdf

38 European Union, Shared Vision, Common Action: A stronger Europe. A global strategy for the European Union's

Foreign and Security Policy, 23 available at https://eeas.europa.eu/sites/eeas/files/eugs review web 0.pdf

${ }^{39}$ Mark Scott, How the Zest struggled to combat digital foreign interference. Politico, 12 November 2019

https://www.politico.eu/article/misinformation-disinformation-uk-general-election-canada-facebook
} 
This predominant interest in foreign disinformation campaigns by bad actors was for a number of years seen as an issue that was detached from the larger enabling role of platforms in the dissemination of disinformation. This started to change in official documents from 2018 onwards. When the European Commission announced the creation of a High Level Group to advise on policy initiatives "to counter fake news and the spread of disinformation online", it vaguely hinted at the need to define "roles and responsibilities of all relevant stakeholders with attention to the functioning of social networks and other online platforms". ${ }^{40}$ The subsequent report of the High Level Group in March 2018 highlighted, for the first time in an official EU document, the need for access to data to understand the systems that enable the circulation of news online. ${ }^{41}$ This request was the result of the presence of four different categories of stakeholders in the panel on the High Level Group: the publishers, fact-checkers, advertisers and academics.

- News media organisations and publishers claimed that they - as "trustworthy organizations" should be allowed to better understand how "algorithms impact the distribution of their services and products". ${ }^{42}$ They wanted to receive a heads up before major changes were made to search and news feed algorithms in order to adjust their online practices. ${ }^{43}$

- The fact-checkers claimed that they could not evaluate the impact of their work (such as the reduced reach of the debunked piece of content via downgrading in the newsfeed, or effectiveness of the automatic display of related articles in dissuading people from sharing the link) without greater transparency.

- Advertisers also stressed that access to this data would provide them with more transparency related to the placement of their ads, which would "avoid misplacements and unintended funding of disinformation" 44 .

- The academics called on the EU to set up a network of independent European Centres for (academic) research on disinformation, which should, inter alia, "provide a safe space for accessing and analysing platforms' data and for a better understanding of the functioning of algorithms" ${ }^{45}$.

Despite these particular motivations, the overall reasons to feature access to platform data prominently in the report was twofold: (1) access to platforms' data is key to better understand the dissemination patterns of digital disinformation, and (2) any independent evaluation to assess any initiative that aims to reduce the spreading of disinformation requires the sharing of data with outside researchers. ${ }^{46}$

One month after the release of the report, the European Commission took on board most of its recommendations, stressing explicitly that "the mechanisms that enable the creation, amplification and

\footnotetext{
40 European Commission, Call for applications for the selection of members of the High Level group on Fake News, 12 November 2017, available at https://ec.europa.eu/digital-single-market/en/news/call-applications-selectionmembers-high-level-group-fake-news

${ }^{41}$ European Commission, Final report of the High Level Expert Group on Fake News and Online Disinformation, 12 March 2018 available at https://ec.europa.eu/digital-single-market/en/news/final-report-high-level-expert-group-fakenews-and-online-disinformation

42 Idem at p.16.

43 Idem at p.16.

44 Idem at p. 25.

45 Idem at p.6.

46 Idem at p.14, 20, 22. As an example, the report highlights how some platform companies, like Facebook and Google, "have experimented with flagging links to disinformation on their products and services or highlighting factchecking work. To evaluate the effectiveness of such responses, platform companies should set out a clear timeline for sharing information on how many links are flagged, what percentage of overall content surfaced this represents, and other data that allows independent third-parties including fact-checkers and researchers to evaluate impact. To ensure these responses do not have adverse consequences, it is also important that they work on appeals processes and make clear how these appeals work". Idem at 26.
} 
dissemination of disinformation rely upon a lack of transparency and traceability in the existing platform ecosystem and on the impact of algorithms and online advertising models". Hence, the Commission stated that it was "necessary to promote adequate changes in platforms' conduct" and "a more accountable information ecosystem" ${ }^{47}$.

To this end, the Commission suggested a two-stage response. Firstly, it would set-up a Code of Practice, which would commit online platforms and the advertising industry to provide academia with "access to platform data (notably via application programming interfaces), while respecting user privacy, trade secrets, and intellectual property". This would "enable them to better understand the functioning of related algorithms and better analyse and monitor disinformation dynamics and their impact on society". ${ }^{48}$ Secondly, the Commission announced it would launch "a secure European online platform on disinformation to support the independent European network of fact-checkers and relevant academic researchers" 49 , which would become known as the European Digital Media Observatory.

Access to proprietary data and the need for 'algorithmic accountability' became increasingly seen as a necessary aspect for any policy response that aims to counter the dissemination of disinformation online. Independent researchers were seen as pathfinders that could: (a) dig up evidence of harmful practices that are facilitated by the core infrastructure of the platforms and (b) scrutinize the effectiveness of voluntary initiatives, which in both cases could require legislative intervention from the EU. In March 2019, European Commissioner Julian King "urged the platforms to do more to improve independent scrutiny" and to ensure that the platforms are "not just marking their own homework". ${ }^{50}$ In June 2019, the Commission said that "cooperation with researchers will enable a better detection and analysis of disinformation campaigns (..) and independent oversight of the functioning of algorithms". ${ }^{51}$ The topic came up several times in autumn 2019 during the confirmation hearings of the Commissioners-designate in the European Parliament. High Representative/Vice-President of the European Commission Josep Borell advocated for "better transparency rules and better cooperation when it comes to access to data and the use of algorithms" in the context of countering disinformation ${ }^{52}$.

\section{Platform promises to provide access to data in the EU Code of Practice on Disinformation}

In September 2018, Facebook, Google, Twitter, Mozilla, and the advertising industry (represented by a number of trade associations) agreed on a Code of Practice, which identified 15 actions divided into five thematic 'pillars' that signatories could voluntarily implement to counter disinformation: (i) improve the scrutiny of ad placements, (ii) ensure transparency about political and issue-based advertising, (iii) adopt

\footnotetext{
${ }^{47}$ European Commission, $\operatorname{COM}(2018) 236$ final, Tackling online disinformation: a European approach, 26 April 2018 https://eur-lex.europa.eu/legal-content/EN/TXT/PDF/?uri=CELEX:52018DC0236\&from=EN p 7

${ }^{48}$ European Commission, Memo 18-3371, Tackling online Disinformation, 26 April 2018, available at https://ec.europa.eu/commission/presscorner/detail/en/MEMO 183371

49 Idem

50 Julian King, Remarks at the Press Conference for the 18th Security Union Progress Report, 20 March 2019 , available at https://ec.europa.eu/commission/commissioners/2014-2019/king/announcements/commissioner-kingsremarks-press-conference-18th-security-union-progress-report-and-progress-made en

51 European Commission, Last intermediate results of the EU code of Practice against disinformation. 14 June 2019 , available at https://ec.europa.eu/digital-single-market/en/news/last-intermediate-results-eu-code-practice-againstdisinformation

52 Answers to the European Parliament - Questionnaire to the Commissioner-Designate Josep Borrell, 2019 , available at https://ec.europa.eu/commission/commissioners/sites/commcwt2019/files/commissioner ep hearings/replies-ep-questionnaire-borrell.pdf
} 
policies on what constitutes impermissible use of automated systems, (iv) empower consumers and (v) empower the research community. ${ }^{53}$

Under the last 'fifth pillar', the signatories "acknowledged" the importance to "take the necessary measures to enable privacy-compliant access to data for fact-checking and research activities" and to "cooperate by providing relevant data on the functioning of their services, including data for independent investigation by academic researchers and general information on algorithms." Hence relevant signatories committed to "support good faith independent efforts to track disinformation and understand its impact" and stated explicitly that "this will include sharing privacy protected datasets, undertaking joint research, or otherwise partnering with academics and civil society organizations if relevant and possible" 54. Relevant signatories also committed not to "prohibit or discourage good faith research into Disinformation and political advertising on their platforms". ${ }^{55}$ The signatories only committed to undertake those actions which correspond to the product or service they offer and "their technical capabilities". ${ }^{56}$

The code was criticized from its outset for not including any meaningful benchmarks to assess the activities of the signatories. In practice, the Commission asked the three platform signatories Google, Twitter and Facebook to self-report on a monthly basis on their actions undertaken in the run-up to the European Parliament elections in May 2019. A so-called "sounding board" that included representatives of the media, civil society, fact checkers and academia stated that the Code

contains no common approach, no clear and meaningful commitments, no measurable objectives or KPIs, hence no possibility to monitor process, and no compliance or enforcement tool: it is by no means self-regulation, and therefore the Platforms, despite their efforts, have not delivered a Code of Practice. ${ }^{57}$

This initial criticism became a common refrain, including by the Commission itself, which admitted in January 2019 that it was 'deeply concerned by the platform's failure to provide specific benchmarks to measure progress, by the lack of detail on the actual results of the measures already taken and lack of detail showing that new policies and tools are deployed timely and with sufficient resources across all EU Member States' ${ }^{58}$. In its final assessment of the Code of Practice the Commission singled out the lack of access so data as "a fundamental shortcoming" of the Code. ${ }^{59}$ The provision of data and search tools required to detect and analyse disinformation cases was seen as "episodic and arbitrary", and did "not respond to the full range of research needs". The voluntary nature of existing data sharing mechanisms was seen as insufficient and hence "a more structured model for cooperation between platforms and the research community should be developed". ${ }^{60}$

\footnotetext{
${ }^{53}$ EU Code of Practice on Disinformation, available at https://ec.europa.eu/digital-single-market/en/news/codepractice-disinformation

54 Idem. Emphasis added

${ }^{55}$ EU Code of Practice on Disinformation, available at https://ec.europa.eu/newsroom/dae/document.cfm?doc id=54454

${ }^{56}$ EEU Code of Practice on Disinformation, available at https://ec.europa.eu/digital-single-market/en/news/codepractice-disinformation

57 The sounding board's unanimous final opinion on the so-called code of practice, 24 September 2018, available at https://ec.europa.eu/newsroom/dae/document.cfm?doc id=54456

${ }^{58}$ European Commission, First monthly intermediate results of the EU Code of Practice against disinformation, 28 February 2019, available at https://ec.europa.eu/digital-single-market/en/news/first-monthly-intermediate-results-eucode-practice-against-disinformation

59 This assessment was based on two other audit reports which came to the same conclusions. See ERGA Report on Disinformation: Assessment of the implementation of the Code of Practice, 2019, available at http://ergaonline.eu/wp-content/uploads/2020/05/ERGA-2019-report-published-2020-LQ.pdf

60 European Commission Staff Working Document, Assessment of the Code of Practice on Disinformation Achievements and areas for further improvement. SWD (2020), 10 September 2020, available at
} 


\section{Mechanisms provided by the platforms to provide access to platform data}

Since the adoption of the Code of Practice, platforms have pointed to three different mechanisms which signal their commitment to make data available to researchers: public APIs, data access grants and partnerships, and quasi transparency reports about their efforts to counter disinformation in the form of reports to the European Commission. This paper will focus on the first two mechanisms to provide access to data to researchers because they have been heralded by platforms - in particular Facebook - as some of the key measures platforms have undertaken to provide more transparency. Essentially, they have been sold as the keys to the kingdom.

Public APIs existed already before the Code of Practice and for long have been regarded as "perhaps the most valuable resource that platforms have offered to third party researchers" 61 . They allow third parties to request machine-readable data in bulk, on a range of relevant topics. Twitter, for instance, has provided for years relatively generous access to public tweets in real-time via its open Streaming API and to historical data via its Search API, which explains why many studies in the field of disinformation disproportionally focus on the use of that platform ${ }^{62}$. YouTube has a similar access regime which allows the downloading of public YouTube data about channels, videos, and searches. In the wake of the Cambridge Analytica scandal Facebook shut down Instagram's public API and substantially reduced the functionalities of Facebook's APIs that provided data on public activities on its public events, groups and pages. ${ }^{63}$ Alexander Sängerlaub for instance argued that after this reduction he was unable to replicate his own research on the 2017 German federal elections. ${ }^{64}$ From October 2019, Facebook also made data available to pre-vetted researchers via its Crowdtangle API. The data available to researchers through Crowdtangle describes aggregated interactions with Facebook and Instagram posts from public pages, public groups, or public people, including engagement data such as the number of user reactions, shares, comments, and comparisons to a benchmark which illustrates over-or under performance for each type of interaction. ${ }^{65}$

These APIs all provide access to public datasets, which pose limited GDPR-concerns. Hence it is no surprise that signatories of the Code quickly narrowed their activities to "support good faith independent efforts to track disinformation and understand its impact" - as required by the Code ${ }^{66}$ - to providing access via APIs to non-personal data, in this case about political ads in public political ads databases. From the three platforms that set up political ad archives (Google, Twitter and Facebook), Facebook's example acts as a cautionary tale about the limits of self-regulation in this area. By leaving it up to the platforms to

https://ec.europa.eu/digital-single-market/en/news/assessment-code-practice-disinformation-achievements-andareas-further-improvement, p.12. Study for the assesment of the implementation of the Code of Practice on disinformation. 8 May 2020, available at https://ec.europa.eu/digital-single-market/en/news/study-assessmentimplementation-code-practice-disinformation

61 Jef Ausloos, Paddy Leerssen, Pim ten Thije, Operationalizing research access in platform governance: What to learn from other industries? Algorithm watch, 25 June 2020, available at https://algorithmwatch.org/wpcontent/uploads/2020/06/GoverningPlatforms IViR study June2020-AlgorithmWatch-2020-06-24.pdf, p 17

62 Tufekci, Zeynep. 2014. Big questions for social media big data: Representativeness, validity and other methodological pitfalls. In Eighth International AAAI Conference on Weblogs and Social Media

63 Axel Bruns (2019): After the 'APIcalypse': social media platforms and their fight against critical scholarly research, Information, Communication \& Society, DOI: 10.1080/1369118X.2019.1637447 at p.7.

${ }^{64}$ Alexander Sangerlaub, Der blinde fleck digitaler Öffentlichkeiten. March 2019, available at https://www.stiftungnv.de/sites/default/files/blinde.fleck .digitale.oeffentlichkeit.pdf

${ }^{65}$ Garmur, Matt; King, Gary; Mukerjee, Zagreb; Persily, Nate; Silverman, Brandon, 2019, "CrowdTangle Platform and API", https://doi.org/10.7910/DVN/SCCQYD, Harvard Dataverse, V3, p.8. For instance the 'benchmark comments' are the expected number of comments a post should have after a given amount of time.

${ }^{66}$ EU Code of Practice on Disinformation, https://ec.europa.eu/digital-single-market/en/news/code-practicedisinformation 
decide how they should implement their obligations under the fifth pillar of the Code of Practice the access to data regime for researches remained an empty box. It is important to dwell on this topic since the ad library and its API have been sold many times by senior executives as an example of how Facebook was a responsible corporate citizen that could be trusted to fix its own problems. In response to Twitter's announcement that it would cease all political ads on its platforms, Sheryl Sandberg for instance responded that Facebook does not have to cease political advertising because the platform is "focused and leading on transparency" explicitly citing Facebook's ad archive efforts. ${ }^{67}$

\subsection{The documented flaws of Facebook's Ad Archive API}

In the run up to the May 2019 European Parliament elections, Facebook announced the introduction of new tools on online advertising to protect the integrity of the elections, amongst others the launch of an Ad Library ${ }^{68}$. According to Facebook, the ad library lets people "easily see how many political and issues ads were run in a given country - as well as aggregated advertiser spend and top searched keywords in the Ad Library". ${ }^{69}$ However, while ordinary users could indeed relatively quickly look up individual ads to a certain extent, research access to the library's data was more problematic.

75 independents researchers, brought together by the Mozilla Foundation, argued that many meaningful data points were missing from the archive, including targeting criteria, impression data, engagement data and data about microtargeting ${ }^{70}$. Independent researchers and civil society organisations accused Facebook of "blocking the ability of independent researchers to effectively study how political disinformation flows across its ad platform". It has been reported that in response, and in private, Facebook has "responded to concerns raised about its ad API's limits by saying it cannot provide researchers with more fulsome data about ads — including the targeting criteria for ads - because doing so would violate its commitments under the EU's General Data Protection Regulation (GDPR) framework". ${ }^{71}$

Moreover, the tool Facebook built was so flawed that it was seen as "effectively useless as a way to track political messaging" 72 . Researchers that had originally set out to track political advertising ahead of the European elections in May 2019 "instead ended up documenting problems with Facebook's library after managing to download the information they needed on only two days in a six-week span because of bugs and technical issues, all of which they reported to Facebook"73. A study by the French Government confirmed the same findings. ${ }^{74}$

67 https://twitter.com/QuickTake/status/1189731760571072513?s=20

68 Facebook, Ads Transparency in the EU, March 2019 available at https://about.fb.com/news/2019/03/adstransparency-in-the-eu/

${ }^{69}$ All elements of the Ad Library are defined in this document

https://socialscience.one/files/partnershipone/files/ad library api codebook.pdf

${ }_{70}$ Mozilla, Facebook and Google: This is what an effective Ad Archive API looks like, 27 March 2019 available at https://blog.mozilla.org/blog/2019/03/27/facebook-and-google-this-is-what-an-effective-ad-archive-api-looks-like/

${ }^{71}$ Natasha Lomas, blocking the ability of independent researchers to effectively study how political disinformation flows across its ad platform. Techcrunch, 29 april 2018, available at https://techcrunch.com/2019/04/29/facebookaccused-of-blocking-wider-efforts-to-study-its-ad-platform/

72 Matthew Rosenberg, Ad tool Facebook built to fight disinformation doesn't work as advertised. New York Times, 25 July 2019, available athttps://www.nytimes.com/2019/07/25/technology/facebook-ad-library.html

73 Idem

74 See French Ambassador for Digital Affairs, Facebook Ads Library Assessment, available at https://disinfo.quaidorsay.fr/en/facebook-ads-library-assessment. For an extensive overview of flaws relating to the Ad library API see https://adtransparency.mozilla.org/eu/log/ For an overview of the effectiveness of the ad library in the Italian, Czech and Dutch elections for the European Parliament see European Partnership for Democracy, Virtual Insanity? The need to guarantee transparency in digital political advertising - available at https://epd.eu/wpcontent/uploads/2020/04/Virtual-Insanity-synthesis-of-findings-on-digital-political-advertising-EPD-03-2020.pdf 


\subsection{Data access partnerships}

Facebook has also experimented with more bespoke, targeted schemes for scholarly data access. The most prominent one is Social Science One, which was announced in April 2018 as a new partnership between independent researchers and Facebook "to study the impact of social media on democracy and elections, generate insights to inform policy at the intersection of media, technology, and democracy, and advance new avenues for future research"75. This 'new approach for industry-academic partnerships' has been pioneered by Gary King (Harvard) and Nate Persily (Stanford) who decided to set up a trusted 'third party' - Social Science One, whose members consist of a commission of senior academics who came to an agreement with Facebook on the scope of a research project ${ }^{76}$.

Social Science One's press release in July 2018 initially promised the release of "about a petabyte of data with almost all public URLs Facebook users globally have clicked on, when, and by what types of people, including many links judged to be intentionally false news stories by third party fact checkers" ${ }^{77}$ Ultimately, in September 2019, it released a limited data set of 7 gigabytes, comprising 32 million URLs that have been shared on Facebook. The long delay resulted in significant criticism from the original funders of Social Science One, who criticized that the 83 independent scholars whose proposals were selected for funding received "access to only a portion of what they were told they could expect, and this has made it difficult or, in some cases, impossible for them to complete the approved research"78. One year and a half after the initial announcement of Social Science One, in December 2019, its co-chairs and its European Advisory Committee stated that "Facebook has still not provided academics with anything approaching adequate data access". They stated:

The current situation is untenable. Heated public and political discussions are waged over the role and responsibilities of platforms in today's societies, and yet researchers cannot make fully informed contributions to these discussions. We are mostly left in the dark, lacking appropriate data to assess potential risks and benefits. This is not an acceptable situation for scientific knowledge. It is not an acceptable situation for our societies". ${ }^{79}$

The reasons for the delay were twofold. Initially, Social Science One thought that researchers could do their research using Facebook's systems, but according to founder Nate Persily in Nature "the company did not have structures that could be readily adapted to give parties access to specific data" ${ }^{\prime \prime 0}$. Hence a

\footnotetext{
75 Social Science One https://socialscience.one/

${ }^{76}$ Idem. The process then continues as follows: The partnering company will then provide the commission access to relevant company data and answer questions. The commission identifies relevant datasets and issues a series of Requests For Proposals; outside scholars submit proposals, which are selected on the basis of academic and social merit (excluding proposals which violate privacy or existing legal agreements/obligations, infringe on ongoing investigations, or put a company at a competitive disadvantage). Those chosen will receive privacy-preserving access to the data and retain the freedom to publish research findings on agreed upon topics without pre-approval from the participating company (except for express violations of law or endangerment to privacy). If the company breaches this agreement in any way, such as withholding relevant information, the commission has the right and the obligation to publicly report the violation.

77 Social Science On: Public Launch, 11 July 2018, available at https://socialscience.one/blog/social-science-onepublic-launch

${ }^{78}$ Funders Supporting Independent Scholarly Access to Facebook Data, Letter to the Social Science Research Council, 27 August 2019, available at https://ssrcstatic.s3.amazonaws.com/sdi/resources/SMDRG funder letter august 2019.pdf

${ }^{79}$ Social Science One, Public statement from the Co-Chairs and European Advisory Committee of Social Science One, 11 December 2019, available at https://socialscience.one/blog/public-statement-european-advisory-committeesocial-science-one

${ }^{80}$ Elizabeth Gibney, Privacy hurdles thwart Facebook democracy research. Nature, 3 October 2019, available at https://www.nature.com/articles/d41586-019-02966-x
} 
customised "unprecedented research infrastructure" had to be built from scratch in order to secure the privacy of the data sets ${ }^{81}$, using differential privacy techniques.

The key rationale put forward by Facebook, however, was that they were constrained by restrictions in both the General Data Protection Regulation (GDPR) from the European Union and the "consent decree" they operate under with the US Federal Trade Commission ${ }^{82}$. Facebook argued that those restrictions "prevent researchers from analyzing individual level data, even if de-identified or aggregated". ${ }^{33}$ Despite these being the key rationale to prevent access to such data, no detailed reasons have ever been provided. Indeed, Facebook's interpretation of those constraints have only been described in broad brushstrokes, or informally at panels, which led the Social Science One co-chairs and its European advisory committee to urge the "major digital platforms" to offer formal, written analyses of any legal barriers they claim prevent them from providing access for academic research, including with regards to the European Union's General Data Protection Regulation (GDPR)". ${ }^{84}$ The academics argued that the GDPR supported "a more permissive interpretation with respect to academic data sharing for public good". ${ }^{5}$

The end-result was a compromise, where Social Science One complied "with Facebook's interpretation of the applicable privacy laws" ${ }^{\prime 6}$, which resulted in applying differential privacy techniques to the URL dataset. This introduced statistical noise and censoring into the dataset which meant that the usefulness of the research was significantly curtailed ${ }^{87}$ Despite the good faith efforts of many people involved in this project who genuinely wanted to make this a success, the history of Social Science One is an example of the limits of voluntary data-sharing approaches between platforms and researchers, where access to data is determined exclusively by the interpretation of the GDPR by one dominant platform.

Most recently, Facebook introduced the US 2020 election research initiative ${ }^{88}$, which pairs a group of outside scholars with internal Facebook employees to study Facebook's and Instagram's impact on four key outcomes that have dominated public and academic attention: political participation, political

\footnotetext{
${ }^{81}$ Facebook Reports on Implementation of the Code of Practice on Disinformation, April 2019 report, available at https://ec.europa.eu/newsroom/dae/document.cfm?doc id=59225

82 FTC, Facebook Settles FTC Charges That It Deceived Consumers By Failing To Keep Privacy Promises, available at https://www.ftc.gov/news-events/press-releases/2011/11/facebook-settles-ftc-charges-it-deceived-consumersfailing-keep. In November 2011 Facebook agreed to settle Federal Trade Commission charges that it deceived consumers by telling them they could keep their information on Facebook private, and then repeatedly allowing it to be shared and made public. The proposed settlement requires Facebook to take several steps to make sure it lives up to its promises in the future, including obtaining consumers' express consent before their information is shared beyond the privacy settings they have established

83 Gary King, Nathaniel Persily, Unprecedented Facebook URLs Dataset now Available for Academic Research through Social Science One, 13 February 2020 available at https://socialscience.one/blog/unprecedented-facebookurls-dataset-now-available-research-through-social-science-one

${ }^{84}$ Social Science One, Public statement from the Co-Chairs and European Advisory Committee of Social Science One, 11 December 2019, available at https://socialscience.one/blog/public-statement-european-advisory-committeesocial-science-one

85 Gary King, Nathaniel Persily, Unprecedented Facebook URLs Dataset now Available for Academic Research through Social Science One, 13 February 2020 available at https://socialscience.one/blog/unprecedented-facebookurls-dataset-now-available-research-through-social-science-one

86 Idem

87 idem.

${ }^{88}$ Nick Clegg, Chaya Nayak, New Facebook and Instagram Research Initiative to Look at US 2020 Presidential Election, 31 August 2020, available at https://about.fb.com/news/2020/08/research-impact-of-facebook-andinstagram-on-us-election/
} 
polarization, knowledge and misperceptions, and trust in US democratic institutions ${ }^{89}$. Only Facebook employees will be able to "touch" and analyze the raw data ${ }^{90}$, but "both teams will work together to devise appropriate monitoring systems for assuring the scientific integrity of the research". This is an important, and promising, new development, but nevertheless there are still limitations to this voluntary approach. While Facebook seems to have internal research teams that can easily pair with external researchers in the US, it is not clear to what extent this initiative could be replicated in the EU, let alone by other major platforms.

\section{Independent trusted third parties and 'safe harbors' as alternatives for voluntary data sharing arrangements}

Platforms' voluntary commitments to make data available to researchers have been characterized by legal and technical snafus. Unilateral changes to earlier APIs with little to no notice to independent researchers have seriously hindered research that would have a clear public interest. Despite the goodwill and genuine efforts from a number of platform representatives and the research community to make data access mechanisms a success, the results have been patchy at best and illustrative of the major power asymmetries between the platforms and the independent researchers.

One option researchers have used to overcome this asymmetry of power, in which platforms unilaterally determine control over access to data, has been to simply scrape data from the platforms without any form of oversight or approval. While this approach has a number of scientific limitations, it has been done for noble purposes, such as ProPublica's use of a browser plug that collected information about political ads and why those ads were being shown to a particular Facebook user ${ }^{91}$. But scraping has been used for more nefarious purposes as well, most notoriously by ClearView Al, a facial recognition company which scraped Facebook and Twitter for images of people's faces.

A more future-proof option is to create an independent 'Trusted Third Party', similar to existing centers in Belgium and France, which provide a secure environment in which accredited researchers, working on approved projects, can access data. The Belgian implementation law of the GDPR allows recourse to a Trusted Third Party to share personal data with third parties for further processing for research purposes. More specifically, this Trusted Third Party, which must be independent from both the initial and the subsequent controllers, is in charge of anonymising or pseudonymising the personal data prior to their communication to the subsequent controller. ${ }^{92}$ Under the Belgian law, the Trusted Third Party could be a natural or legal person, a de facto association or a public body. ${ }^{93}$ This mechanism also exists in the UK ${ }^{94}$ and in France, where the Centre for Secure Access to Data aims at organizing and implementing secure access services for confidential data for non-profit research, study, evaluation or innovation. ${ }^{95}$

\footnotetext{
${ }^{89} 2020$ Election Research Project, A Proposal for Understanding Social Media's Impact on Elections: Rigorous, PeerReviewed Scientific Research, 31 august 2020 https://medium.com/@2020 election research project/a-proposalfor-understanding-social-medias-impact-on-elections-4ca5b7aae10

90 Idem

91 Nick Statt, Facebook blocks third-party tools that collect information on political ads. The Verge, 28 January 2019 available at https://www.theverge.com/2019/1/28/18201361/facebook-political-ad-transparency-tools-blocked-userdata-privacy

${ }_{92}$ Article 202 of the Belgian Law implementing the GDPR "Wet van 30 juli 2018 betreffende de bescherming van natuurlijke personen in verband met de verwerking van persoonsgegevens".

${ }^{93}$ Idem, Article 188.

94 See https://uksa.statisticsauthority.gov.uk/about-the-authority/committees/nsdec/adrn/

${ }^{95}$ For more info see https://www.casd.eu/en/
} 
Ausloos and others correctly identify the strengths of such an independent institution, which can act as a bridge between those holding the data and those wishing to get access to that data. Such a trusted third party can act as a "neutral arbiter" in deciding on requests for confidentiality from the disclosing party and in periodically auditing disclosing parties to verify the accuracy of disclosures" ${ }^{96}$ They can "maintain relevant access infrastructure" and "verify and pre-process corporate data in order to ensure it is suitable for disclosure". ${ }^{97}$ Ultimately they could even play a role in "ensuring otherwise unavailable or uninterpretable data to be made accessible" because "the fact that data is not readily available and/or produced by the respective platforms, should not be a reason to discard including that data into the access regime". In the platform context, Ausloos and others suggest that a "more centralized EU-level institution" could be advisable given the "the political-economic power and multinational dimensions of platform operators. ${ }^{98}$

Such a trusted-third party could host what others have called 'research safe harbors', which would allow "researchers to access data without worrying that they are breaching laws", as suggested for instance by Larry Kramer, president of the William and Flora Hewlett Foundation ${ }^{99}$. However it is important to always unpack what exactly is meant with 'safe harbour' proposals, as they could refer to a number of different things. Research safe harbours could be understood as implying the creation of a new legal immunity for the platform providing data under a set of agreed conditions, which would prevent platforms to be held liable for any potential misuse of the data by the researcher. ${ }^{100}$ Such an interpretation would be controversial in the post Cambridge Analytica era, which demonstrated that processing activities that initially aim to pursue a research purpose can be misused and lead to serious data protection concerns. Similarly, safe harbors are also sometimes used as referring to regulatory sandboxes where authorized stakeholders would be allowed to test specific processing of personal data regardless of the applicable data protection laws. While such regulatory sandboxes are a useful tool to assess the adequacy of a legal framework without hindering innovation, they do not represent a long-term solution to solve our current incentives problem. Indeed, such regulatory sandboxes are usually used for a limited period of time and do not necessarily lead to an adaptation of the legal framework.

To avoid confusion it might be better to not use the term 'safe harbor' but to refer to 'clean rooms' or 'data rooms' to describe a set of practices to share sensitive data with a third party. The "clean rooms" is most commonly used by the manufacturing industry in reference to secure environments for scientific research, semiconductor device fabrication or the production of pharma products ${ }^{101}$. But certain platforms, like Facebook, have used it to share user information with advertisers. In this case the platform provides a "safe space" where marketing data can be shared and manipulated in ways that are completely secure

\footnotetext{
96 Jef Ausloos, Paddy Leerssen, Pim ten Thije, Operationalizing research access in platform governance: What to learn from other industries? Algorithm watch, 25 June 2020, at 84, available at https://algorithmwatch.org/wpcontent/uploads/2020/06/GoverningPlatforms IViR study June2020-AlgorithmWatch-2020-06-24.pdf.

97 Idem at 87-88.

98 Idem at 84.

99 Hanna Murphy, First project studying how Facebook affects elections runs into privacy concerns. Financial Times, 30 september 2019 available at https://www.ft.com/content/6133b90e-e23f-11e9-9743-db5a370481bc

100 Jef Ausloos, Paddy Leerssen, Pim ten Thije, Operationalizing research access in platform governance: What to learn from other industries? Algorithm watch, 25 June 2020, at 91 arguing that "far-reaching immunities for disclosed data could create a moral hazard and push platforms towards carelessness, increasing the risk of harmful content being disclosed".

101 Allison Schiff, Facebook Shares More Audience Data Via Carefully Controlled 'Clean Rooms'. Ad Exchanger, 28 july 2017, available at https://www.adexchanger.com/platforms/facebook-shares-audience-data-via-carefullycontrolled-clean-rooms/
} 
from external access. ${ }^{102}$ In the context of EU antitrust and merger investigations so-called "data rooms" have been used on a number of occasions as well, mainly for the disclosure of quantitative data such as sales data, price data or cost data. ${ }^{103}$ While such a trusted third party would be a clear improvement over the current situation, it is clear that such a mechanism would need to be coupled with a new legal mandate that would force platforms to hand over relevant data to that body, especially if that data would include (sensitive) personal data. Before exploring how such a mechanism could work in the future it is crucial to assess to what extent platforms are already able to share such personal data, which is the topic of the next section.

\section{Assessing the appropriate legal basis for the sharing of personal data with independent researchers}

Until now we have highlighted the valid reasons that independent researchers have to demand access to platform data, including personal data. These demands have been acknowledged and supported by various officials and bodies of the EU, who are equally interested in having access to platform data to hold platforms to account for their role in facilitating and amplifying disinformation as part of a new regulatory framework. Partly as a result of this political pressure some platforms have provided voluntary access mechanisms to provide access to a limited subset of predominantly public or anonymised platform data, including via public APIs, or data access grants and partnerships. These mechanisms are not seen as sufficient, both by researchers and European policy makers, for a variety of reasons.

One crucial reason a number of platforms have invoked for this limited appetite to expand the sharing of (personal) data is their obligations under the EU's General Data Protection Regulation. Europe's general data protection regulation (GDPR) contains a basic premise: personal data can only be processed by a 'data controller' if there is one of six applicable legal bases for that activity ${ }^{104}$. In this case, the data controllers are the platforms that organise, collate and determine the purposes of processing. ${ }^{105} \mathrm{By}$ disseminating, transmitting and making such data available to independent researchers, those data controllers will be engaging in an act of processing. ${ }^{106}$

A very strict interpretation of these obligations by the platforms argues that the GDPR would not allow the sharing of personal data from the platform to a researcher, while a more nuanced interpretation argues that the GDPR would not allow the sharing of personal data without taking precautions that in practice result in platforms only making available anonymous data or aggregated data. Whether those interpretations are true or not is subject to arguments. However, the fact that it requires an argument is in itself a barrier to hand over data. This uncertainty is both undesirable for both researchers and the platforms.

This paper's understanding of both interpretations is based on informal discussions with - and presentations of - platform representatives in the past two years under Chatham House rules, since the

\footnotetext{
102 Karen Moked, Post-GDPR, are data clean rooms the answer to accessing walled gardens? Digital Content Next, 15 August 2018 https://digitalcontentnext.org/blog/2018/08/15/post-gdpr-are-data-clean-rooms-the-answer-toaccessing-walled-gardens/

${ }^{103}$ See European Commission, DG Competition, Best Practices on the disclosure of information in data rooms in proceedings under Articles 101 and 102 TFEU and under the EU Merger Regulation, https://ec.europa.eu/competition/mergers/legislation/disclosure information data rooms en.pdf

104 GDPR article 5(1)(a). The GDPR creates a higher threshold of protection for the processing of "special category" personal data, which includes data revealing political opinions or religious or philosophical beliefs. GDPR art. 9.1 105 GDPR article 4(7)

106 GDPR article 4(2)
} 
major platforms have to date not offered formal, written analyses of specific GDPR-barriers they have identified to share personal data with researchers.

Hence, section 6 of this paper scrutinizes the first argument, and argues that the GDPR currently would allow platforms to share personal data based on consent or legitimate interest ${ }^{107}$, while two other legal bases (public interest and legal obligation) could be used in the future as a legal basis. Section 6.4 in particular argues that the creation of a new separate legal obligation imposed on the platforms would create extra legal certainty in the future for both researchers and platforms, which would be particularly useful to share special category data that reveal a person's political opinions or religious or philosophical beliefs. Section 7 of this paper then provides an initial assessment of some of the more detailed questions that arise in relation to the GDPR's research exemption in article 89, which are relevant to consider independent from the legal basis of the data processing.

\subsection{Consent}

Personal data could be shared with independent researchers if the data subject has given his consent to the platform to share his personal data ${ }^{108}$. Consent under the GDPR has specific requirements and a high threshold to be considered valid. Valid consent needs to be freely given, specific and informed, and granted by an unambiguous affirmative action. ${ }^{109}$ Note that one of the main bases for processing special category data is 'explicit' consent ${ }^{110}$.

In addition to the threshold difficulties associated with consent, relying on consent would pose a number of other difficulties for platforms. For example, including a clause in the non-negotiable Terms of Service of a platform that states that 'by using this platform you agree that your data will be shared for research purposes' is presumably not freely given due to the power imbalance between the user and the platform, and hence a platform would likely not be able to rely on consent as a legal basis to share personal data with an independent researcher. ${ }^{111}$

Furthermore, users of a specific platform would need to fully understand in advance the purpose of the research in order for their consent to be 'specific and informed'. This isn't always feasible - especially in the sort of big data research that characterizes the field of disinformation scholars. Research usually happens after the data was collected, which makes it hard to provide 'informed' consent a priori. The GDPR accommodates this reality of academic research via the research exemption in article 5.1.b (see

\footnotetext{
107 The other legal bases for the sharing of personal data, as identified in article 6 of the GDPR are not relevant in this context. GDPR article $6.1 \mathrm{~d}$ would allow for the sharing of personal data 'in order to protect the vital interests of the data subject', but the transfer of data for research purposes is unlikely to be necessary to protect the "vital interests" of individuals. GDPR article $6.1 \mathrm{~b}$ also provides a lawful basis for the processing of personal data if the processing is 'necessary for the performance of a contract to which the data subject is a party'\#, for instance when personal data needs to be processed as part of an employment contract. It is difficult to see how this legal basis would apply to platforms sharing data to researchers, as platforms would have to expressly specify that data would be shared with third party researchers to have access to their personal data for general research purposes. It is hard to see how such terms would be "necessary" for the performance of such a contract and as such, it is unlikely that this would be a suitable basis. To rephrase: a contract between Facebook and a user to give the latter access to Facebook's services would not require such a clause to achieve the purpose of giving a user access to Facebook.

108 GDPR article 6.1.a

109 Article 4(1)(11) of GDPR.

110 GDPR article 9.2(a).

${ }^{111}$ European Data Protection Board, Guidelines 05/2020 on consent under regulation 2016/679, version 1.1, adopted on 4 May 2020 at 13.
} 
section 7$)^{112}$, and users could in principle also consent to a platform sharing their data for more general research purposes ${ }^{113}$ or on an ad hoc basis, where a platform asks as a selection of their users whether they would want to contribute their data for a specific and well delineated research project. But the practical implications of relying on consent are not trivial. Researchers would need to be able to accommodate requests of users who withdraw their consent - which under the GDPR should be possible at any time during the research, and in a way that is as easy as giving consent ${ }^{114}$. This can have a significant impact on the research process and its conclusions. Requesting consent can also reduce the ultimate utility of a data set for researchers, since users that opt-in to a study may not be representative of the relevant population the researcher is intended to study. In addition, users who consent in this way may change their behaviors precisely because they know those behaviors are being studied

\subsection{Legitimate interest}

Personal data could also be shared for the purposes of the legitimate interests pursued by the platform or by the researcher. ${ }^{115}$ In a 2017 case, the Court of Justice of the European Union has held that if a controller (in this case, the platform) wants to rely on legitimate interests as a legal basis it has to satisfy a challenging three-part test. ${ }^{116}$

First, the platform has to demonstrate that the interest that is being pursued is legitimate. Carrying out scientific research is considered to be a legitimate interest ${ }^{117}$, but this interest must be "sufficiently clearly articulated to allow the balancing test to be carried out against the interests and fundamental rights of the data subject". ${ }^{118}$ It could be argued that it would be difficult for platforms to balance these interests without having detailed knowledge in advance about the research purpose, aims and analytical methods of a specific research request. However, requiring this information from a researcher in advance can jeopardize the independence of the researchers, and the legitimacy of any resulting study, since a platform would in theory be able to just deny access if it does not like a particular topic of a research project.

Even less desirable, the platform would also need to show that a specific research methodology is "necessary" to achieve those aims. Finally, the balancing test would require the platform to analyse to

\footnotetext{
112 Article 5.1.b GDPR states that further processing of data for scientific purposes shall not be considered to be incompatible with the purpose limitation principle.

113 GDPR recital 33, European Data Protection Board, Guidelines 05/2020 on consent under regulation 2016/679, version 1.1, adopted on 4 May 2020 available at

https://edpb.europa.eu/sites/edpb/files/files/file1/edpb guidelines 202005 consent en.pdf pp.30-31.

114 GDPR article 7.3

115 GDPR article 6(1)(f)

${ }^{116}$ CJEU Case C-13-16, Valsts policijas Rīgas reǵiona pārvaldes Kārtības policijas pārvalde v Rīgas pašvaldības SIA 'Rīgas satiksme', 4 May 2017 at para. 28: "In that regard, Article 7(f) of Directive 95/46 lays down three cumulative conditions so that the processing of personal data is lawful, namely, first, the pursuit of a legitimate interest by the data controller or by the third party or parties to whom the data are disclosed; second, the need to process personal data for the purposes of the legitimate interests pursued; and third, that the fundamental rights and freedoms of the person concerned by the data protection [sic] do not take precedence."

117 The Article 29 working party stipulated that a "well-considered use" of legitimate interest as a legal base to provide access to data is especially relevant for "historical or other kinds of scientific research, particularly where access is required to certain databases". The Article 29 Working Party was an advisory body made up of a representative from the data protection authority of each EU Member State, the European Data Protection Supervisor and the European Commission, which interpreted the Data Protection Directive, the predecessor of the GDPR. Its successor is the European Data Protection Board (EDPB). Opinion 6/2014 on the Notion of legitimate interests of the data controller under Article 7 of Directive 95/46/EC (WP217)

118 Article 29 Working Party, Opinion 06/2014 on the notion of legitimate interests of the data controller under Article 7 of Directive 95/46/EC, p.24
} 
what extent the processing activity of the researcher might pose a risk to the fundamental rights of the data subject ${ }^{119}$, which would require inter alia knowledge of the procedural, contractual and other safeguards that researchers are planning to put in place to safeguard the personal data and identities of the data subjects.

In summary, platforms could rely on legitimate interest as a legal basis to transfer data, but relying on this legal basis requires measures could result in platforms acting as de facto gatekeepers that are able to decide on the validity of specific research proposals and methods, which would be an undesirable situation. This concern is also valid when platforms would rely on consent as a legal basis to provide access to data, since the platforms would still need to assess the necessity and legitimacy of the purpose for the research design. As a result, two alternative legal bases could be more promising in the future to provide such access to data.

\subsection{Public interest}

In theory, platforms could share data with independent researchers if this form of processing is "necessary for the performance of a task carried out in the public interest". ${ }^{120}$ In section 1 this article demonstrated why giving access to independent researchers would be in the public interest. It would enable the

- attribution of organised disinformation campaigns

- assessment of the effectiveness of voluntary platform policies to counter disinformation,

- detect societal harms that can result from platform activities. ${ }^{121}$

However, platforms might be cautious in using this ground as a legal basis for transferring data to independent researchers for two reasons. Firstly, the GDPR does not provide a definition of "public interest"; it merely states that such a "public interest" must be based on EU or Member State law. One could argue that Article 2 of the Treaty on the European Union states that "democracy" is a foundational value of the EU, and hence any activity that aims to analyze how democracy is being disrupted by platforms and/or third parties using platforms could be seen as a measure that is taken in the public interest. But this interpretation hasn't been tested by the Courts.

Secondly, providing speedy access at scale to massive amounts of personal data for public interest reasons needs to meet the necessity test ${ }^{122}$, ie. is it strictly necessary for platforms to share this data in order to achieve the public interest goal at stake? One could argue that that necessity test is likely to be met given the importance of understanding how disinformation is distributed and amplified via platforms for society, but again this is an untested interpretation by the courts and subject to debate ${ }^{123}$.

Adding to this complexity is the fact that whereas platforms might be able to rely on public interest as a legal basis to share personal data with researchers, this would not be possible for the sharing of special category data. The GDPR would only allow the sharing of special category data if such sharing is

\footnotetext{
119 Recital 47 GDPR

120 GDPR article 6(1)(e)

121 See also Ausloos et al p.13.

122 For more info on this test see https://edps.europa.eu/sites/edp/files/publication/17-0601 necessity toolkit final en $0 . p d f$

123 The EDPS has called for a "debate on the circumstances in which access by researchers to data held by private companies can be based on public interest." European Data Protection Supervisor, A preliminary opinion on data protection and scientific research, 6 January 2020, p.2.
} 
necessary for reasons of substantial public interest. ${ }^{124}$ This is a higher threshold than the 'ordinary' 'public interest' test described above. The British Information Commissioner's Office has explained that it is not enough to make a "vague or generic public interest argument" - one should be able to "make specific arguments about the concrete wider benefits of your processing". ${ }^{125}$ Such a substantial public interest would also need to be explicitly based on EU or Member State Law, and hence without such an explicit legal basis it is "difficult, if not impossible" to view a 'substantial public interest' as a basis for processing special category data for scientific research purposes ${ }^{126}$ at the moment. ${ }^{127}$ Much of the data that researchers would need to analyze, detect, expose or prevent the creation, facilitation, dissemination and impact of disinformation online would likely fall in the category of special category data that reveals, for instance, political opinions.

Ultimately, it is clear that the GDPR is set up for (substantial) 'public' interest to be qualified and interpreted in a number of different ways. ${ }^{128}$ This could be done by an opinion of the EDPB or via a Code of Practice in order to avoid legal uncertainty (see section 8 of this paper) So while in theory platforms could be sharing data with researchers on the public interest basis, ideally a separate legal basis is created at the EU-level that forces platforms to hand over data, including special category data, for public interest purposes (see the scenario outlined in section 6.4).

\subsection{Legal obligation}

A platform would be able to share data with independent researchers if this sharing is "necessary to comply with a legal obligation" to which the platform is subject ${ }^{129}$ in EU law or a national Member State law. There is currently no such legal obligation at EU-level that would force platforms to share (personal) data for general research or auditing purposes, but the GDPR does allow each EU member state to introduce such specific legislation fairly rapidly ${ }^{130}$ to impose such an obligation.

However, such a legal obligation could be included in ongoing regulatory initiatives of the European Union, such as the Digital Services Act (DSA) or the European Action Plan on Democracy. Let's envisage the following thought experiment. As highlighted in section 2, European policy makers have often emphasized the need for access to data for researchers. The Digital Services Act could include a carefully crafted, precise list of public policy goals which (a specific subset of) platforms have to meet to protect the general public, or specific subsets of the population such as minors. Examples of such goals should be in line with provisions in the European Convention on Human Rights and can include goals such as the protection of public health ${ }^{131}$ and the protection of free elections ${ }^{132}$. Consequently, in the field

124 GDPR article 9.2.g. This would not apply to special category data that were 'manifestly made public'. Nonprotected tweets, personal data posted on public Facebook pages and groups or public YouTube comments that reveal a certain political opinion would all generally fall into this category. Status updates on private pages or discussions in closed groups would not fall into this category. GDPR article 9.2.e

$125 \mathrm{ICO}$, what are the substantial public interest conditions, available at https://ico.org.uk/for-organisations/guide-todata-protection/guide-to-the-general-data-protection-regulation-gdpr/special-category-data/what-are-the-substantialpublic-interest-conditions/

${ }^{126}$ See also European Data Protection Supervisor, A preliminary opinion on data protection and scientific research, 6 January 2020, at p.23

127 European Member States can authorize research involving special categories of personal data for specific research topics in national GDPR implementation laws.

128 GDPR article 6.3 and 23.1.e

129 GDPR article 6(1)(c)

130 GDPR article 6.2

131 European Convention of Human Rights, article 10.2

132 European Convention of Human Rights, Protocol 1, article 3. 
of disinformation, this could be translated as the need to protect the general public from health misinformation or election manipulation.

Subsequently, the DSA should oblige platforms to take all necessary and proportionate measures to achieve these goals. The object of regulation is the management of platform behaviour vis-à-vis disinformation on their services, and not the content itself. These due diligence measures should not only be limited to taking actions against third party actors that abuse the Terms of Services of these platforms. They should also include measures that address the distribution and amplification mechanisms involved in the proliferation of disinformation. Active design choices which lie at the heart of certain gatekeepers' business model are responsible for shaping users' access to information, its amplification, and ultimately the reach of specific pieces of content, which are key elements to detect and respond to disinformation campaigns. At a minimum, a due diligence obligation would include an obligation to do risk assessments and carry out risk mitigation measures on an ongoing basis of the risks brought by the functioning, deployment and use of these content distribution and amplification mechanisms.

This governance framework can only work on one condition: strong powers ensuring appropriate transparency from the platform vis-à-vis an independent regulator, which should have the power to demand any type of granular information that is necessary for it to fulfil its supervisory tasks and monitor the compliance of companies with their obligations in relation to the DSA.

To conduct a robust algorithm inspection or audit regime, the competent authority would need a clear legal mandate to demand access to all relevant data - to the extent that such access is necessary to monitor and assess compliance of platforms with their obligations under the DSA. As part of this regime, a regulator could for instance have the power to instruct a pool of pre-vetted independent researchers to undertake an audit on its behalf, which includes providing access to platform data to undertake audits. ${ }^{133}$

This isn't a far-fetched scenario. As illustrated above, major platforms signed the EU Code of Practice on Disinformation, in which they recognized to

"take the reasonable measures to enable privacy-compliant access to data for fact-checking and research activities and to cooperate by providing relevant data on the functioning of their services including data for independent investigation by academic researchers and general information on algorithms". ${ }^{134}$

This option would not force platforms in a de facto role of gatekeepers for public research, overcomes practical obstacles that are related to asking consent from data subjects and provides more legal certainty for both researchers and platforms. Such a separate legal basis would still leave a number of questions unanswered regarding the precise modalities, types of data and safeguards researchers would need to adhere to in order to safeguards the rights of the data subjects. These questions could be addressed in a separate Code of Conduct between platforms and researchers (see section 8).

133 See also Jef Ausloos, Paddy Leerssen, Pim ten Thije, Operationalizing research access in platform governance: What to learn from other industries? Algorithm watch, 25 June 2020, p.79. "A clear legal obligation to share data upon request is essential in creating a robust and meaningful access regime for platform data. It is also important that this obligation only relates to a well-defined, legally circumscribed, and trusted independent institution (instead of, for example, researchers requesting access directly from the platform of interest)"

$134 \operatorname{COM}(2018) 236$ final. 


\section{Perceived legal uncertainties related to the GDPR's research-exemption in article 89}

From the section above it is clear that there are two legal bases that currently allow for the sharing of personal data from platforms to public interest researchers (consent and legitimate interest), whereas public interest as currently laid down by Union law or domestic law does not extend to cover research ${ }^{135}$. However, determining the appropriate legal basis for sharing data is only a first step. Once that legal basis is known, the platform - in its role as controller - also needs to take into account a number of principles before it can share data. These principles include that the platform has to ensure that the data is shared in accordance with the purposes for which they were collected ("purpose limitation" ${ }^{136}$ ), ensure that technical and organisational measures are put in place in order to respect the principles of data minimisation ${ }^{137}$, accuracy ${ }^{138}$, storage limitation ${ }^{139}$, and preserving the integrity and confidentiality of the data $^{140}$. The platforms also would need to adhere to a number of transparency obligations. ${ }^{141}$

The drafters of the GDPR implicitly conceded that adhering to all these principles might be difficult in a research context, and hence introduced a number of derogations to some of these principles. Importantly, the sharing of special category data may be allowed if this is seen as necessary for archiving purposes in the public interest, scientific or historical research purposes if the processing complies with the requirements imposed by Article 89 (1) of the GDPR. ${ }^{142}$ As this article made clear in section 6 , special category data might be processed for research purposes that have a basis in EU or Member State law. Additionally, there are three other crucial derogations: (1) the GDPR presumes that sharing data for research purposes is considered to be compatible with the initial purposes of data collection ${ }^{143},(2)$ personal data used for research may be exempt from the exercise of individual rights, such as the right to request access to your data, ${ }^{144}$ and (3) the exemption of the need to provide data subjects with specific pieces of information ${ }^{145}$.

Despite these exceptions, it appears that platforms perceive there to be other obstacles to hand over personal data to be in the implementation of these principles as laid down in Article 5 of the GDPR. Whether those obstacles are true or not is subject to arguments. However, the fact that it requires an argument is in itself a barrier to hand over data. This uncertainty is both undesirable for both researchers and the platforms. In the following paragraphs this paper will attempt to highlight legal uncertainties in the GDPR which cause platforms to be reluctant in providing access to data for research purposes.

\subsection{Determining the validity of a 'research' project}

One obstacle that some platforms have brought up in discussions is that they should not be placed in a position to define whether a specific activity qualifies as 'research' under the GDPR. The GDPR does not

135 GDPR art. 6.1.3

136 GDPR art. 5.1.b

137 GDPR art. 5.1.c

138 GDPR art. 5.1.d

139 GDPR art. 5.1.e

140 GDPR art. 5.1.f

141 GDPR art 13.

142 GDPR art. 89.1 "Those safeguards shall ensure that technical and organisational measures are in place in particular in order to ensure respect for the principle of data minimisation. Those measures may include pseudonymisation provided that those purposes can be fulfilled in that manner. Where those purposes can be fulfilled by further processing which does not permit or no longer permits the identification of data subjects, those purposes shall be fulfilled in that manner."

143 GDPR art. 5.1.b

144 GDPR art. 17.3.d and art. 89.2.

145 GDPR art. 14.5.b 
explicitly define research but simply states that it should be interpreted "in a broad manner" including for example "technological development and demonstration, fundamental research, applied research and privately funded research"146. The EU has always used such a broad interpretation of the notion of research, which is illustrated by Article 179 of the Treaty on the Functioning of the European Union that specifies that 'the Union shall have the objective of strengthening its scientific and technological bases by achieving a European research area in which researchers, scientific knowledge and technology circulate freely'.

However, this is a rather artificial argument from the platforms. Both the European Data Protection Supervisor and the European Data Protection Board have clarified that the application of the special data protection regime for scientific research applies to research where "relevant sectoral standards of methodology and ethics apply"147, or where a research project is "set up in accordance with relevant sector-related methodological and ethical standards, in conformity with good practice". ${ }^{148}$ In private, certain platforms have pointed out that they do not want to be in a position to determine whether a research proposal is in line with those relevant sectoral standards. But while platforms would need to assess the data protection safeguards of a specific project, they would not need to assess this particular aspect. This requirement is likely to be met when an Institutional Review Board has given its blessing to the methods proposed for research. To avoid further doubt, this is a topic that could be dealt with in a Code of Conduct (see section 8).

\subsection{Determining the quality of data protection safeguards that have been implemented by the researcher}

A second, similar, obstacle that platforms perceive relates to uncertainty around the relaxation of the purpose limitation rule, and the precise safeguards that a research project needs to include in order to process personal data. Under Article 5(1)(b) GDPR, researchers can receive data which were initially collected by the platform for different purposes in order to subsequently use these for research. However, to benefit from this relaxed rule the receiving researcher needs to implement "appropriate safeguards" to protect the rights and freedoms of the data subject. ${ }^{149}$ According to the EDPS this doesn't provide "a general authorisation" to further process data in all cases for historical, statistical or scientific purposes. Instead, "each case must be considered on its own merits and circumstances". ${ }^{150}$ Again, platforms have argued that they don't want to be the arbiter that decides which types of technical, organisational, procedural or contractual safeguards should be implemented in a research project before data can be shared. This is a more legitimate concern. For example, the EDPB has specified that in scientific research, data minimisation can be achieved "through the requirement of specifying the research questions and assessing the type and amount of data necessary to properly answer these research questions"151. Platforms don't want to be making that assessment as it could have an impact on the independence of the research.

146 GDPR recital 159.

${ }^{147}$ European Data Protection Supervisor, A preliminary opinion on data protection and scientific research, 6 January 2020, p 10-12

${ }_{148}$ European Data Protection Board, Guidelines 05/2020 on consent under Regulation 2016/679, 4 May 2020 at 143 https://edpb.europa.eu/sites/edpb/files/files/file1/edpb guidelines 202005 consent en.pdf

149 GDPR art.89.1

150 European Data Protection Supervisor, A preliminary opinion on data protection and scientific research, 6 January 2020 , p.22.

${ }^{151}$ EDPB, Guidelines 03/2020 on the processing of data concerning health for the purpose of scientific research in the context of the COVID-19 outbreak, available at

https://edpb.europa.eu/sites/edpb/files/files/file1/edpb guidelines 202003 healthdatascientificresearchcovid19 en.pd $\underline{f}$ at 46 
Platforms also argue that article 89.1 requires them to determine whether the research objective can be achieved using anonymous information. However, while the GDPR encourages anonymization of personal data as a way to mitigate risks for the data subject ${ }^{152}$, it is not the sole option to provide appropriate safeguards to processing activities for research purposes. Article 89 of the GDPR specifically includes pseudonymisation as a potential alternative especially if the purpose of the research cannot be achieved without the processing of personal data. Platforms similarly argue that the guidance from the Article 29 Working Party on anonymisation techniques contains contradictions and is confusing. On the one hand, the document sets a very high bar to achieve anonymity; it states that data are seen as anonymous data if the process to strip the data of identifiable elements is "irreversible"153. At the same time however, it also allows for a lower bar, suggesting that an anonymization process "is sufficiently robust" if "identification has become reasonably impossible" 154 . These are two different standards that seem hard to reconcile, but they should be seen as mere examples of how anonymisation can be achieved. ${ }^{155}$ There is no "prescriptive standard" in EU legislation and several anonymisation techniques can be used.

Some of these concerns could be overcome when an independent entity or an independent sector-wide association of researchers outline in a research protocol which safeguards should be implemented, such as the extent to which the research can be done by using pseudonymous data (so as to supply only the least identifiable information to achieve the research objective) or which security standards and limitations on the retention of personal data would need to be considered. However, no such sector-wide entity or association exists and IRB and other ethics boards are decentralized entities, residing within each university. This is another set of questions that could be solved by the Code of Conduct (see section 8).

\subsection{Platforms claim they cannot rely on the more relaxed transparency requirements that the GDPR offers to researchers}

The GDPR requires platforms to provide their users with relevant information about the purposes of the processing of their data and the recipients of any personal data collected. ${ }^{156}$ If a platform would want to further process personal data for a purpose other than that for which it was obtained, it would need to provide the data subject with more information on that other purpose and "any other relevant further information". ${ }^{157}$ Translation: if a platform makes data available for research purposes to independent researchers, it would need to inform all its affected users at a minimum of a) the purpose of that research and $b$ ) the identities of those researchers. However, the GDPR has explicit exceptions to that principle when that further processing is for research purposes. ${ }^{158}$ Without this derogation, any form of big data research in practice would be rendered very difficult in the EU.

Certain platforms question however whether they could rely on this exception, stating that this exception would only apply to those cases where data is obtained indirectly, for example by a third party from a platform, but not when a platform itself obtains that data directly from its users. ${ }^{159}$ The argument here is

\footnotetext{
152 The European Data Protection Board has noted that "anonymisation is the preferred solution as soon as the purpose of the research can be achieved without the processing of personal data". https://edpb.europa.eu/sites/edpb/files/files/file1/edpb guidelines 202005 consent en.pdf at 31.

${ }^{153}$ Article 29 Working Party https://ec.europa.eu/justice/article-29/documentation/opinionrecommendation/files/2014/wp216 en.pdf p.5

154 Idem p.8.

155 Idem p. 6

156 GDPR art 13.

157 GDPR art 13.3

158 GDPR art 5.1b, article 14.5b, 89.2 and 89.3.

159 See GDPR article 13.
} 
that while it would be virtually impossible for researchers to track down every individual whose data they received from the platform, the same isn't true for a platform that itself collected that information. ${ }^{160}$ While this is a disputable argument, it is a matter that can be dealt with in a Code of Conduct.

\subsection{Dealing with different national GDPR-implementation laws}

One of the most challenging aspects related to the GDPR in general is that it has left quite some discretion to the member states of the European Union to implement the law. Different Member States have different rules regarding how special category data and personal data are allowed to be processed for research purposes ${ }^{161}$. The research exceptions that exclude the application of some of the data subject rights, such as rights to access or rectification, can also vary from member state to member state $^{162}$. This means in practice that personal data that was made available by a platform for research purposes could be subject to different regimes for individuals to exercise their rights, depending on which member state law applies. Finally, Member States have adopted their own rules to specify which member state law would apply in situations of cross-border processing activities (such as cross-border research). In the context of pan-European research projects it could therefore be unclear to know which Member State law applies; the applicable law could be that of the jurisdiction in which the platform is established or where the data subject is located (or both). To date there is - to the best of my knowledge - no publicly available exhaustive overview available that spells out which legal research regime applies in which Member State - which creates uncertainty (and frustration) among researchers and platforms. These local deviations provided by national legislation do not prevent the sharing of data with researchers but they do create an incentive to limit sharing according to the rules of the Member State with the most restrictive processing rules.

\section{The need for a Code of Conduct on Access to Platform Data}

From sections 6 and 7 above it is clear that platforms currently have little incentives to share special category data and personal data with independent researchers. How can this incentive problem and perceived lack of legal certainty be solved? In addition to the key general recommendation in section 6.4 to create a clear legal obligation for platforms to share personal data with researchers, further legal guidance would be appropriate to spell out, for instance, the conditions for processing special categories of personal data for research purposes, or the appropriate safeguards that must be adhered to.

There are three options to provide that guidance.

Firstly, regulatory guidance from the European Data Protection Board could clarify a number of these concerns. While such guidance is not binding, it would remove a number of perceived legal risks for platforms to share data with the research community in order to scrutinize disinformation-related questions. Secondly, guidance can come from a national data protection authority. Platforms can carry out a data protection impact assessment prior to sharing data with researchers in order to analyse on a

\footnotetext{
${ }^{160}$ Art 29 Working Party, Guidelines on transparency under regulation 2016/679 at para 62. "The only difference between an Article 13 and an Article 14 situation is that in the latter, the personal data is not collected from the data subject. It therefore follows that impossibility or disproportionate effort typically arises by virtue of circumstances which do not apply if the personal data is collected from the data subject. In other words, the impossibility or disproportionate effort must be directly connected to the fact that the personal data was obtained other than from the data subject".

161 GDPR art. 9.2.j

162 EDPB at 55-56

https://edpb.europa.eu/sites/edpb/files/files/file1/edpb guidelines 202003 healthdatascientificresearchcovid19 en.pd $\underline{f}$
} 
case by case basis any concerns they might have related to the design of a study or its safeguards for users. ${ }^{163}$ Given the perceived risks described in sections 6 and 7 of this paper, that platform could subsequently alert the relevant national supervisory body (the national data protection authority (DPA). In that scenario, the supervisory authority should within a period of eight weeks provide written advice to the platform, and, if needed, to the researcher. ${ }^{164}$ Through this process, the national DPA could provide certainty about which appropriate technical and organisational safeguards would need to be implemented before data can be shared, which is especially relevant when national laws stipulate concrete technical requirements or other safeguards such as adherence to professional secrecy rules ${ }^{165}$. In theory, the national DPA could ultimately even certify these practices, ${ }^{166}$ which would provide legal certainty to both the platform and the researcher.

However, there are two serious limitations to this approach. National DPA's can't currently cope with all the requests they are receiving and as such might not be eager to engage in such a process. Secondly, as described above, most research questions in the field of disinformation are likely to contain personal data from a range of European Member States, and a national DPA is likely to be reluctant to interpret the national implementation of the GDPR from another member state. This would also likely trigger the cooperation mechanism in the GDPR, where supervisory authorities must try to work together with other supervisory authorities and reach a mutual agreement where possible ${ }^{167}$. Such a process can take years to be completed.

The third option seems to be the most promising one to achieve in the medium term more legal certainty for both researchers and platforms on a pan-European scale: the creation of a bespoke Code of Conduct on access to platform data, which meets the needs for legal certainty for both platforms and researchers.

Article 40 of the GDPR provides that EU Member States, data protection authorities, the EDPB and the Commission shall encourage the adoption of such Codes of Conduct that specify the application of the GDPR for a specific sector or context. According to the EDPB, such a Code should aim to codify how the GDPR shall apply in a "specific, practical and precise manner". ${ }^{168}$

Associations of academics in a specific field, trade associations which represent platforms, consortia of associations or any other body that represents a relevant sector in this field may (jointly) prepare such codes; they become the 'Code Owners'169.

They can specify the application of the GDPR on most of the challenges that were identified in section 7 , including on

(a) who should be considered a legitimate 'researcher'

(b) what is considered to be fair and transparent processing,

163 GDPR art 35.

164 GDPR art. 36.2

165 EDPB at 51

https://edpb.europa.eu/sites/edpb/files/files/file1/edpb guidelines 202003 healthdatascientificresearchcovid19 en.pd f

166 GDPR art. 42

167 GDPR art.60

168 EDPB at 15

https://edpb.europa.eu/sites/edpb/files/files/file1/edpb guidelines 201901 v2.0 codesofconduct en.pdf

169 EDPB guidelines

https://edpb.europa.eu/sites/edpb/files/files/file1/edpb guidelines 201901 v2.0 codesofconduct en.pdf p.7. The EDPB specifies that the Code Owners must demonstrate that they are an effective representative body and that they are capable of understanding the needs of their members and clearly defining the processing activity or sector to which the code is intended to apply." EDPB pp. 11-12. 
(b) the legitimate interests pursued by the researchers,

(c) the necessary safeguards to anonymize or pseudonymize personal data,

(d) the extent, timing and scope of the information about the research protocol that needs to be given to both the data subjects and the broader public,

(e) the extent to which data subjects can exercise their rights in the context of the potential limitations of those rights,

(f) measures to ensure data protection by design and the security of processing. ${ }^{170}$

The European Data Protection Supervisor encouraged the adoption of such a Code of Conduct, and specifically added that such a Code can include "the provision by private companies, particularly tech platforms, of data to independent researchers for specific projects, such as examining online manipulation and the dissemination of misinformation". ${ }^{171}$

Such a transnational Code of Conduct on Access to Platform Data should ideally establish a monitoring body ${ }^{172}$, which scrutinizes the compliance of the platforms and research associations with the Code and which carries out reviews of the Code's operations. The EDPB specifies that this body needs to have at its disposal effective mechanisms, including "random and unannounced audits, annual inspections"173, "reporting requirements, clear and transparent complaint handling and dispute resolution procedures, concrete sanctions and remedies in cases of violations of the code, as well as policies for reporting breaches of its provisions". ${ }^{174}$

This Monitoring Body can be internal or external to the Code Owners. For this code, it seems preferable to choose an external body given the diversity of the potential participants, which has full autonomy for the budget and other resources. ${ }^{175}$ Importantly, the Monitoring Body can sanction those members who break the rules of the code. ${ }^{176}$ Sanctions can include a range of suitable corrective measures, which aim to stop the infringement and avoid future recurrence including the suspension or exclusion of Members from the Code ${ }^{177}$. Importantly, the drafters of this code need to submit a draft Code to the relevant national data protection authority ${ }^{178}$, which needs to approve the Code provided that it complies with the GDPR. The relevant supervisory authority can enforce against and fine the monitoring body if it does not fulfill its duties.

170 GDPR art.40.2.

${ }^{171}$ European Data Protection Supervisor, A preliminary opinion on data protection and scientific research, 6 January 2020 , p.26.

172 GDPR art 41.1

173 EDPB at p.23

https://edpb.europa.eu/sites/edpb/files/files/file1/edpb guidelines 201901 v2.0 codesofconduct en.pdf

${ }^{174}$ EDPB at $p 16$

https://edpb.europa.eu/sites/edpb/files/files/file1/edpb guidelines 201901 v2.0 codesofconduct en.pdf

$\overline{175}$ For more details see EDPB at pp 21-22

https://edpb.europa.eu/sites/edpb/files/files/file1/edpb guidelines 201901 v2.0 codesofconduct en.pdf

176 GDPR art. 41.2.b and c

177 GDPR art 41.4. The EDPB specifies that "remedial actions and sanctions could include such measures ranging from training to issuing a warning, report to the Board of the member, a formal notice requiring

the implementation of specific actions within a specified deadline, temporary suspension of the member from the code until remedial action is taken to the definitive exclusion of such member". At para 76

https://edpb.europa.eu/sites/edpb/files/files/file1/edpb guidelines 201901 v2.0 codesofconduct en.pdf from the code".

178 The EDPB lists a numbers of factors that could take into account the to decide which DPA is relevant: (1) The location of the largest density of the processing activity or sector; (2) the location of the largest density of data subjects affected by the processing activity or sector; (3) the location of the code owner's headquarters; (4) the location of the proposed monitoring body's headquarters; or (5) the initiatives developed by a supervisory authority in a specific field. EDPB p.28

https://edpb.europa.eu/sites/edpb/files/files/file1/edpb guidelines 201901 v2.0 codesofconduct en.pdf 
For a transnational code like this one the competent supervisory authority must subsequently refer the code to the EDPB for a decision ${ }^{179}$, and from there, it proceeds to the European Commission ${ }^{180}$ which can decide that the approved Code of Conduct has general validity within the European Union. The Code of Conduct then ends up as an implementing act in EU law ${ }^{181}$.

As a result, such a Code of Conduct can actually have teeth and be enforced. As the EDPB points out: As outlined in Recital 77 and Article 24(3) of the GDPR, adherence to an approved code of conduct is envisaged, amongst others, as an appropriate method for a data controller or processor to demonstrate compliance with regard to specific parts or principles of the Regulation or the Regulation as a whole. Adherence to an approved code of conduct will also be a factor taken into consideration by supervisory authorities when evaluating specific features of data processing such as the security aspects assessing the impact of processing under a DPIA or when imposing an administrative fine. In case of a breach of one of the provisions of the Regulation, adherence to an approved code of conduct might be indicative of how comprehensive the need is to intervene with an effective, proportionate, dissuasive administrative fine or other corrective measure from the supervisory authority. ${ }^{182}$

The advantages of such a Code are clear:

- it would provide a consistent level of data protection throughout the EU and would prevent the types of national divergences for processing activities for research activities.

- It would create a template for researchers that spells out which safeguards they need to adhere to once they get access to platform data, while providing more legal certainty to platforms without encroaching on the independence of the researchers.

- The EDPB rightly points out that such a code could also decrease the level of reliance that platforms and researchers may sometimes place on national data protection authorities " to provide more granular guidance for their specific processing activities". ${ }^{183}$

Which particular steps would need to be taken to establish such a Code? ${ }^{184}$

First, associations of researchers need to identify the scope of the Code of Conduct and its Code Owners. Which platforms need to be covered? Every social media platform or only the emerging category of 'gatekeeper platforms'? Conversely, which associations of researchers can be included? And to what extent can commercial organisations - which play a big role in investigating disinformation campaigns participate? Which research areas should be covered and which data processing activities?

Second, determine the organisational structure, corporate form and operational management of the process that leads to the Code. Given the expected costs of this exercise it would be good to contemplate who will fund these activities as well. In this context, it does make sense to approach the initial founders of Social Science One for this exercise.

Thirdly, develop a consultation plan. The GDPR requires an extensive consultation phase that needs to take place. This consultation shouldn't only relate to the members forming part of the organisation or body

\footnotetext{
179 GDPR art.40.7

180 GDPR art.40.8

181 GDPR art.40.9

182 EDPB, pp.10-11.

183 EDPB p.9 https://edpb.europa.eu/sites/edpb/files/files/file1/edpb guidelines 201901 v2.0 codesofconduct en.pdf

184 See also appendix 3 at p.29 here

https://edpb.europa.eu/sites/edpb/files/files/file1/edpb guidelines 201901 v2.0 codesofconduct en.pdf
} 
acting as the code owner, but also general members of the public, NGO's privacy experts, and journalists. They can all provide input on issues such as the types of data that should be made accessible to researchers, appropriate procedural or technical safeguards or appropriate penalties for non-compliance

Finally, draft the code on the basis of the consultation, establish a monitoring body and present it to the competent supervisory authority.

\section{Conclusion}

The European Commission should introduce a legally binding obligation on platforms to provide access to platform data to independent researchers as part of its ongoing legislative efforts to establish clear responsibilities for online platforms. Such an obligation is necessary to understand the role and impact of platforms in our societies, which in turn can enable evidence-based policies to address perceived societal harms that are facilitated by the core infrastructure of the platforms.

The GDPR currently allows for the sharing of such data, including personal data, on the basis of at least two legal bases: consent and legitimate interest. However, relying on consent results in a number of practical implications which can affect the validity of the research, whereas relying on legitimate interests as a legal basis could result in platforms acting as de facto gatekeepers that are able to decide on the validity of specific research proposals and methods, which would be an undesirable situation. Platforms might be able to rely on public interest as a legal basis to share personal data, but not special category personal data. A platform would be able to share data with independent researchers if this sharing is "necessary to comply with a legal obligation" to which the platform is subject in EU law. There is currently no such legal obligation at EU-level that would force platforms to share (personal) data for general research or auditing purposes, but such a legal obligation could be included in ongoing regulatory initiatives of the European Union, such as the Digital Services Act (DSA) or the European Action Plan on Democracy.

Such a legal obligation would not force platforms in a de facto role of gatekeepers for public research, overcomes practical obstacles that are related to asking consent from data subjects and provides more legal certainty for both researchers and platforms. Such a separate legal basis would still leave a number of questions unanswered regarding the precise modalities and safeguards researchers would need to adhere to in order to safeguards the rights of the data subjects. These questions could be addressed in a separate Code of Conduct between platforms and researchers. 